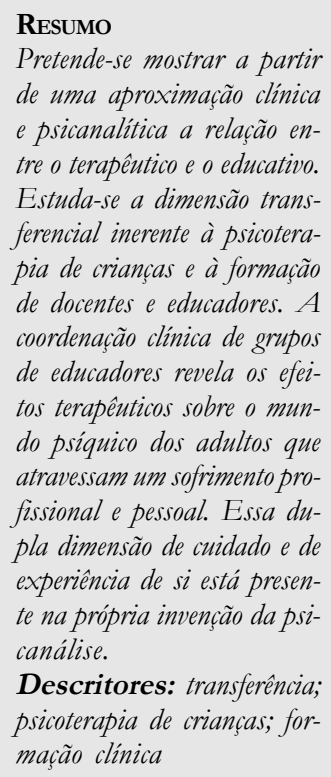

Descritores: transferência; psicoterapia de crianças; formação clínica

\section{O DEBATE ENTRE O CUIDADO E A EDUCAÇÃO: PRÁTICAS CLIINICAS ATUAIS}

\author{
Bernard Pechberty \\ Tradução: Viviane Veras
}

A

partir da temática proposta por Estilos da Clínica, interroguei-me sobre o que me evocava essa ligação proposta entre a educação e a terapêutica. A lembrança de minha visita ao Lugar de Vida com meus colegas brasileiros veio-me à mente, assim como a imagem da força desse trabalho que mobilizava psicanalistas e terapeutas em torno de uma idéia da educação por vir, na escola, com crianças psicóticas. Reencontrei a idéia de que a entrada no laço escolar é diligente, terapêutica, quer dizer, é humanizante, identificadora; esse procedimento inscrevia-se na história de uma abordagem em que os profissionais analistas têm como visada a educação e a escola como cuidado possível da psicose (Kupfer, 2001).

Procurei retomar em outros planos essa associação de dois termos que não recobrem as mesmas realidades na França. Educamos com base em valores familiares ou em campos de sentido como

Professor titular em Ciências da Educação da Universidade Paris V - René Descartes, França. 
a saúde ou o ambiente. Os exemplos que me ocorrem estão ligados às minhas práticas clínicas atuais no cuidado de crianças e adolescentes e na condução de grupos clínicos com docentes e educadores.

A aparição de intervenções que parecem educativas, no domínio do cuidado, da terapêutica, e da psicanálise da criança, levanta questões. $\mathrm{O}$ educativo parece à margem da intervenção do psicanalista, mas ele tem aí uma função essencial. Além do mais - e isso faz laço com a experiência do Lugar de Vida -, essas intervenções "educativas" concernem à clínica de crianças gravemente perturbadas.

\section{O educativo na terapia de crianças psicóticas: a sobrevida do terapeuta}

A dimensão educativa, no sentido primeiro de afirmação de regras e de interditos para viver com os outros, remete-me à clínica de crianças, em particular, autistas, psicóticas, ou transbordadas pelas excitações pulsionais. A literatura clínica descreve, há muito tempo, como o quadro clássico da psicanálise foi modificado, a partir de Ferenczi (Pechberty, 2000), pelo trabalho com pacientes-limite. Com as crianças, Anna Freud propunha, no início de seu trabalho, um tipo de educação com base no dispositivo psicanalítico e sob sua influência, e intervinha, até mesmo, na família da criança. F. Tustin descreve a forma como exige de seu paciente, uma criança autista, que ponha em ordem, junto com ela, a sala de trabalho no final da sessão (Tustin, 1986). Essa atividade partilhada entre a terapeuta e a criança com o objetivo de organizar tem implícitos outros sentidos: delimitar um quadro, marcar o tempo e o fim da sessão, fazer desaparecer o caos que a criança criou na sala como projeção de seu próprio caos, e estabelecer, assim, a diferença entre o espaço psíquico e o espaço material. Serve também para o profissional introduzir um sentido possível, sair da desordem psíquica que a criança lhe transmite nas transferências do encontro terapêutico. Tustin acrescentava que sofria as censuras de psicanalistas da época em relação a essa atividade que ela assumia como analista, essa atividade partilhada, saindo da reserva clássica exigida.

Na minha prática clínica junto às crianças, é também com meus pacientes-limite que não se inscrevem no quadro habitual, que são "ineducáveis" para aceitar as regras do dispositivo, que me sinto no dever de agir, interditar, limitar, lembrar as regras e sustentá-las, talvez, no corpo a corpo com a criança. 
Nordine, 5 anos, vive com sua mãe. Ele mostra um equilíbrio psíquico frágil, exprime reivindicações e cóleras incessantes, sempre se afirmando à beira da depressão. Nordine é encaminhado ao centro médico-educativo: ele passa ao ato, na escola maternal, e agride muito rapidamente as outras crianças. Na sessão, ele é transbordado pelas excitações, rola no chão e põe-se a rir sozinho. Ele busca, escondendo-se, minha resposta, minha intervenção. Se eu entro nesse jogo, a relação se engata por um breve momento, mas Nordine continua, cada vez mais, exige, destrói os objetos, sua onipotência leva-o a atuações em que desafia qualquer resposta possível, por trás da aparência de jogo aparente.

Nordine me leva sempre mais longe, e não posso, enfim, senão interditá-lo e contê-lo, até mesmo no corpo a corpo com ele. Além da irritação que ele me transmite, sinto-me muito educativo intervindo desse modo, mas esses momentos mostram, sobretudo, minha impotência para trabalhar frente a essa repetição de excitações. Uma série de limites restringindo os gritos dessa criança, o respeito imposto pelo quadro fez-me pensar que o que eu fazia era, em primeiro grau, o educativo. Meu objetivo era, contudo, criar um suporte novo para a criança, a fim de entrar em contato com ela, com uma subjetividade possível, oculta por essa excitação sem limite.

Os limites que estabeleci eram de início uma resposta em espelho à violência interna dessa criança; violência que a transbordava, que ela expulsava na sala de atendimento e que direcionava a mim. Nordine estava naquele tempo, descrito por Winnicott, em que a excitação pulsional criada pelo jogo pode destruí-lo (Winnicott, 1971). Eu lhe respondo, sem dúvida em espelho, reacionalmente, como ele esperava, mas também para dar sentido a esse caos, reconstruir um quadro possível. Nessa transação, que era uma passagem ao ato assumida de minha parte, estimava que nesse ponto pudesse estabelecer contato entre os níveis arcaicos da criança e aqueles que ela me fazia experimentar. Ele solicitava também minha parte infantil, violenta, que fazia eco às excitações transmitidas. A partir de então, ele pôde ter momentos de troca, e foi só depois que se revelou para mim a pertinência de minhas intervenções para construir sentido e para promover as trocas possíveis com Nordine.

O que está em jogo no não do terapeuta, no limite, na afirmação de que tudo não é possível? Esse tempo faz existir uma forma que introduz a possibilidade de outra relação. A partir de então, é criada uma situação que permite ao profissional conduzir uma relação terapêutica, condição para um início de subjetivação e de intersubjetividade partilhada entre a criança e o profissional. 
Interditar é, portanto, estabelecer o limite, pela fala, mas, sobretudo, pelo ato; é, portanto, construir um espaço de sobrevida para o terapeuta, para que ele possa continuar a sustentar a situação clínica. Face ao insuportável da loucura, dos processos primários que se impõem, há vários modos de intervenção do profissional: sua interpretação, suas capacidades de invenção a fim de entrar em contato com a criança. Partilhar com o outro um sentido possível - seja sobre os estados psíquicos em jogo com o paciente e ele mesmo, seja sobre a referência a uma realidade externa comum - vai permitir outras experiências, outras dinâmicas. A passagem pela descrição da contratransferência do terapeuta parece-me aqui uma via fecunda para tentar compreender esses momentos.

As intervenções do analista, que tomam conscientemente uma forma educativa: "não faça isso", "pare”, os interditos sobrepostos às atuações destrutivas da criança, esses atos, essas palavras manifestam a presença limitante do terapeuta, que age sobre a forma da comunicação. Esse ato de conotação educativa torna-se então um meio para criar uma relação que é terapêutica pelo fato mesmo de que ela começa a existir, para ele e para o paciente. Sua finalidade é fazer a criança sair de seu gozo pulsional e de angústias arcaicas, é permitir pequenas pontes para uma realidade psíquica ou externa partilhável.

A intervenção educativa mobiliza, assim, as defesas necessárias que visam a abrir possibilidades para o terapeuta e para a criança tratada; o que acontece pelo fazer (ordenar, interditar), pelo interdito. Colocar limites no tratamento toma assim o sentido de uma experiência real, em que o educativo está submetido ao terapêutico, e permite relançar questões por meio das transferências em jogo.

O ponto maior que diferencia a análise da psicoterapia é o trabalho com a transferência. Passar do gozo arcaico a um início de laço que permita um contato, por mínimo que seja, e depois uma relação, é o pedestal terapêutico sobre o qual pode inscrever-se o trabalho psicanalítico. Em termos freudianos, passamos do narcisismo primário ao narcisismo secundário; se nos referimos à contribuição de Lacan, a fase do espelho que se colocaria agora em cena abre para o caminho do estabelecimento da relação com o Outro, lugar de uma simbolização possível.

\section{O laço com os pais}

O trabalho com a criança na sua dimensão de inacabamento e de dependência acentua o sentimento de nossa responsabilidade no trabalho clínico e os fantasmas educativos são solicitados de forma privilegiada, em diversos níveis.

Como sublinhava Maud Mannoni, muitas transferências acompanham a tratamento da criança. Assim, os pais projetam no analista de seu filho um conjunto de imagens; por exemplo, a de ser um educador melhor que eles. Mencionei também a freqüência de um imaginário de tradutor, de intermediário entre eles e 
seu filho, que é também afetado pelo terapeuta. $\mathrm{O}$ trabalho com esses diferentes cenários incita a inovar, a não conceber o quadro do tratamento como rígido. Assim, uma criança pode, em seu tratamento, dar lugar aos pais, que vêm então falar na sessão, na frente de seu filho; ou, mais tarde, na continuidade do trabalho com ele. Uma transferência de forma educativa branda pode assim se estabelecer, uma forma de escuta em que o terapeuta não dá um conselho, mas permite ao familiar vir falar de sua função educativa e das condições inconscientes que aí se atam.

Antoine, 10 anos, vive com Marie, sua mãe, e encontra seu pai regularmente; seus pais estão separados. Ele apresenta crises de cólera, insulta sua mãe, sua irmã, mente e esconde suas avaliações escolares. Vem às sessões, muito cooperativo, mas não diz quase nada, e responde brevemente às minhas questões. No final de um ano, as condutas melhoram e Marie manifesta o desejo de consultar-se comigo depois do trabalho terapêutico realizado com o filho; o que aceito. Mais tarde, Marie virá sozinha. Ela fala então de sua relação materna e educativa com seu filho, das atitudes violentas de Antoine, que evocam as do pai; ela fala de seu modo de exercer a autoridade com seus filhos e dos laços, das repetições que se fazem com seu passado. Nenhum conselho lhe é dado, mas ela trabalha e assume um modo de transferência particular em relação ao terapeuta de seu filho.

Nessas consultas clínicas, parece que Marie cuida de sua função educativa e parental piorada pelos sintomas da criança, e de sua responsabi-

18 Estilos da Clínica, 2007, Vol. XII, n²2, 14-25 
lidade psíquica. A dimensão clínica consistiu aqui em acompanhar certas identificações que remetem à dimensão narcísica, na sua função de espelho entre a criança e os pais. Os temores de Marie organizam-se sobre os conflitos identificatórios de mulher, de mãe presa entre a impotência e a onipotência, e as vacilações da sua própria imagem, que as acompanham. Freqüentemente, com efeito, é com base em uma impossibilidade de educar que a criança e a família vêm se consultar. É depois do encontro com a criança, freqüentemente sintoma da família, que uma abordagem terapêutica da função educativa e parental pode estabelecer uma pequena ponte eventual para um trabalho psicanalítico.

\section{Os docentes em grupos clínicos de análise de práticas}

Abordarei agora a questão do cuidado, do terapêutico nos grupos clínicos de análise das práticas docentes. Esses grupos situam-se na filiação de M. Balint e de Ferenczi, clínicos que permitiram que a psicanálise saísse de seu quadro habitual; o grupal e a prática profissional tornaram-se objetos de um trabalho psicanalítico possível. Os grupos têm lugar no estabelecimento, ou fora, no contexto de formação contínua ou privada. Em um quadro clínico preciso (duração, confidencialidade das trocas, regras de participação), regido pela regra de associação livre dos pensamentos e das experiências, um participante apresenta um relato sobre um momento de sua prática ao qual o grupo vai reagir. Esse relato pode dizer respeito à relação com um aluno, com a classe, com a instituição. Os desvios psíquicos que emergem abrem para falas e sentidos inesperados e afetos passados e presentes.

A análise clínica das práticas é difícil de implantar no meio docente, diferente dos meios de trabalho social ou educativo. Levanto a hipótese de que o que torna difícil o acesso aos grupos clínicos na cultura docente é a história institucional, e ainda a forma dos saberes escolares. A escola constrói precocemente as relações específicas ao saber, estabelece uma série de rupturas na continuidade do desenvolvimento da criança para o aluno e, depois, para o docente.

Esses grupos clínicos permitem no plano subjetivo um relacionamento entre o Si pessoal e profissional e suas atitudes inconscientes; quer dizer, os conflitos psíquicos e a série de condições identificatórias que acompanham a experiência do sujeito docente de hoje (o "si" que se declina em si-aluno, si-docente, si-criança ou siprofissional é um termo que faz eco a self, e é empregado em um sentido próximo ao do termo em Winnicott. Dele será retida a 
preocupação com a dimensão integrativa de diferentes instâncias psíquicas e também o sentimento, ou mesmo a sensação, que a pessoa tem dela mesma). Esse trabalho induz efeitos terapêuticos, de cuidado (no sentido do care winnicottiano) e de compreensão que é necessário precisar. Na Note de synthèse sur les $\mathrm{Re}$ cherches cliniques d'orientation psychanalytique dans le champ de l'éducation et de la formation (Blanchard-Laville, Chaussecourte, Hatchuel \& Pechberty, 2005), insistimos no acompanhamento clínico e na noção de terapia profissional - termo utilizado por C. Blanchard-Laville -, que me parece muito pertinente.

As vinhetas, apresentadas a seguir, surgiram da condução de grupos clínicos e descrevem momentos de encruzilhada, de tempos de tomada de consciência e de deslocamento psíquico na subjetividade profissional que têm efeitos de diminuição da angústia. Retornando às temáticas produzidas em diversos grupos clínicos que conduzi, três dimensões principais parecem se destacar:

A tensão entre as relações duais com um aluno e com a classe como grupo: alguns relatos dizem respeito tanto às ligações amorosas experimentadas por jovens docentes que se implicam demais na vida de seus alunos, quanto a angústias persecutórias, muito freqüentes. Do mesmo modo, a agitação e a excitação de um aluno solicitam a implicação do docente no nível de um reconhecimento, mas, sobretudo, uma resposta, uma tomada de posição. A invasão do espaço psíquico do docente, que então tem lugar, corresponde a uma contratrans- ferência profissional que deve ser elaborada. As questões educativas colocam-se, assim, como as de uma não adaptação ao quadro tradicional da classe em relação a certos percursos dos alunos, à questão das sanções como limites da lei ou à modificação necessária da pedagogia.

$O$ déficit ou o excesso de idealização da relação professor-aluno e seu possivel fracasso: o processo de idealização é o motor, porque mantém o compromisso do docente relativamente a seus alunos. Nessa configuração, vemos que o docente projeta no aluno os elementos narcísicos idealizados que, caso sejam muito importantes, revelam-se inadequados graças à desilusão inevitável. Uma formação clínica encontraria sem dúvida uma de suas razões de ser na elaboração da posição depressiva, e nas condições de formação.

A queixa quanto à instituição, pouco sustentadora ou persecutória: a identificação à instituição e a suas missões entretém uma dimensão infantilizante no encontro com os alunos, os colegas e a hierarquia. Mendel descreveu esses ambientes na sua concepção do psicofamiliar (Mendel, 1993).

Em seguida, destaco outras temáticas recorrentes trazidas pelos participantes dos grupos de análise de práticas.

$\mathrm{O}$ aluno medroso e invejoso: Martine, docente de escola de segundo grau, exprime seu incômodo em relação a seus alunos: ela não ousa entabular um contato pessoal com eles, e descreve-os como francos ou insolentes, mas, sobretudo, ela diz, "muito mais livres que na minha época". Assim, os alunos cochicham, expri- 
mem seu respeito para com a autoridade do docente. A inveja da liberdade de seus alunos, associada ao medo de sua própria agressividade aflora no discurso. $O$ conflito interno delineia-se em torno dessa violência inibida em relação a seus antigos educadores. O relato de Martine fará com que perceba no a posteriori os laços com sua infância, ocasião em que ela correspondia às expectativas dos adultos e de seus pais, dificilmente existentes para ela mesma.

Idealização do si docente e negação da relação com os alunos: Jean, jovem docente do liceu técnico, não aceita o desinteresse manifestado por seus alunos em relação ao curso. Nessa escola que prepara para artes decorativas, os alunos trabalham em boas condições, e têm garantia de encontrar trabalho. $\mathrm{O}$ discurso de Jean aprofunda-se e mostra sua expectativa de satisfações narcísicas diretas: ele queria que seu saber e sua pedagogia fossem imediatamente fascinantes, ele se confunde, sem distância, com uma imagem de docente ideal que deveria ser de saída esperado pelos alunos com os quais ele não tem nenhum contato psíquico. A oposição deles desperta nele uma grande dúvida quanto a suas capacidades, e defende-se dela de modo violento, pretendendo, além disso, modelá-los. O trabalho em grupo faz com que perceba a dimensão reacional da conduta dos alunos em relação a ele, equivalente a uma recusa de entrar nessa imagem ideal dele mesmo que impõe aos alunos.

Si-profissional e identificações parentais: Christiane, professora agregada de matemática, sofre de uma grande solidão profissional com seus colegas. Nomeada para um liceu "chique", ela se vê à parte desses "burgueses". Ela evoca seu trajeto com emoção: de meio modesto, seus pais se sacrificaram para que ela estudasse e se tornasse professora. Seu relato torna claro como seu ideal profissional alcançado foi construído sobre uma dívida em relação aos esforços e sonhos que seus pais depositaram nela. Seu orgulho por ter sido bem sucedida vem acompanhado da culpa e de uma vivência de separação difícil entre eles e o mundo da infância. Uma parte do si-profissional de Christiane está ainda confundida com essa infância. As lembranças fazem notar que os laços que ela mantém com essa marca social de sua infância perturbam-na; ela esquecerá, aliás, de reunir-se ao grupo na sessão seguinte. Esse ato falho põe em cena uma tomada de distância. Ela retornará e dirá, mais tarde, que tem muito a refletir e que pode agora comunicar-se diferentemente com seus colegas, sem pensar que está traindo suas origens.

A impotência na classe: Marine, transbordada pela excitação e pela ausência de trabalho de seus alunos em classe de segundo grau, perde seu controle e põe-se a chorar na frente deles. Os alunos, em sua maioria garotas, ficam aturdidos, fazem silêncio, pedem desculpas. O clima da classe se acalma. Tudo se passa como se um aspecto do si-profissional de Marine desabasse na frente de seus alunos e do grupo. Aqueles restauram então narcisicamente sua professora, introduzindo na relação um laço diferente: a culpabilidade havia fun- 
cionado e os alunos haviam protegido Marine e a situação escolar. Pode-se imaginar, sem grande dificuldade, uma classe menos empática que gozaria por ter atingido o adulto docente em sua fragilidade e daria então livre curso a suas pulsões destruidoras.

Nos exemplos apresentados, o conflito psíquico está presente em cada um, ele incide sobre o desvio entre o ideal e a realidade, e recobre experiências diferentes de dissociação ou de ligação entre o si-docente de hoje e o si-aluno inconsciente sempre ativo. O exemplo de Christiane mostra como uma parte de sua identidade profissional adere aos ideais familiares da infância, o que lhe interdita o contato com seus colegas. A relação de jean com seus alunos é uma negação da relação, ao contrário da dependência afetiva de Marine, identificada de modo fusional com sues jovens alunos.

Esses exemplos podem ajudar-nos a pensar a dimensão do cuidado presente na intervenção clínica nas práticas docentes.

A partir da exposição de uma situação profissional perturbadora, como na análise de um sonho, os desvios psíquicos associativos que levam na direção da escola ou da família acarretam modificações psíquicas, e uma restauração narcísica. Os grupos clínicos elaboram os traços do aluno imaginário que cada um foi e, eventualmente, fragmentos da história familiar que fazem laço com a situação profissional presente. As temáticas dos relatos examinados descrevem freqüentemente o déficit ou a excessivamente completa idealização da experiência de ensino, e a persistência do si aluno ou do si adolescente no docente que se projeta em seus alunos. Os relatos fazem aparecer o conflito psíquico, que se torna preciso no relato do participante, assim como elementos do cenário inconsciente. É, portanto, a presença do narcisismo no exercício da profissão que sustentam essas condutas de idealização, os laços de semelhança ou de diferença entre as representações do si docente e do si aluno; é ainda o narcisismo que organiza as formas de reconhecimento de si (aluno, criança, adolescente) no outro - aluno ou colega, definição inspirada em Freud e Lacan, que me parece fecunda.

As situações trazidas pelos docentes em dificuldade dizem respeito à sua função educativa ou à sua relação ao saber. Quando os docentes não chegam a ensinar, sua relação ao saber é desestabilizada e são as dificuldades pedagógicas e "educativas", no sentido amplo, que vêm ao primeiro plano. $\mathrm{O}$ infantil - outro nome do inconsciente, dizia Freud - vem se repetir aí. Essas identificações educativas concernem às ligações aos alunos, ao saber e à instituição, e reatualizam as condutas psíquicas antigas. A dificuldade de ensinar reativa as angústias, modos de defesa das moções pulsionais. Os modos de autoridade, a disciplina, a sedução na relação pedagógica, a identificação mínima aos alunos de hoje, a confusão de papéis, a dificuldade de estabelecer uma distância relacional per- 
tinente aparecem em espelho com as relações aos alunos que ativam as posições parentais, adolescentes e infantis no docente.

Quando apresentamos esses grupos clínicos, anunciamos que não são grupos terapêuticos; seu objeto não é a história singular dos participantes, mas sua posição profissional e as ressonâncias pessoais - entre elas as inconscientes - em jogo nos grupos. E, contudo, constata-se sempre que há efeitos de cuidado, terapêuticos, sobre as pessoas. Na França, o ensino e o cuidado são historicamente muito distintos. Os termos clínicos, terapêuticos, são associados ao medicinal e o trabalho de referência psicanalítica, evidente na formação de outros meios como os do trabalho social ou educativo é, entre os docentes, objeto de ambivalência e de reações passionais extremas.

O trabalho clínico conduz-nos, contudo, a nuançar essas posições; penso que há certa interdição em pensar os efeitos do cuidado. O levantamento dos recalques e o abrandamento das separações têm efeitos terapêuticos sobre a personalidade profissional. $\mathrm{O}$ grupo clínico autoriza a expressão e a elaboração de ressentimentos, experiências e pensamentos. Mas é no trabalho das relações do si aluno com o si docente de hoje que esses grupos mostram sua mais ampla eficácia de mudança.

Esses grupos permitem, assim, uma elaboração psíquica, os ressentimentos em grupo que mostram a diversidade das moções psíquicas entre os participantes e a comunidade, e sua relação ao inconsciente, a mais singular. Por trás das evocações, são ativados tempos diferentes: o presente, das decisões concretas do docente na sua classe e a trama psíquica inconsciente que se repete. A identificação parental, que recobre a dificuldade de ensinar, o lugar do pai imaginário em relação aos alunos, a aceitação da decepção face à idealização da tarefa são experiências que o grupo clínico permite elaborar.

Esses grupos têm efeitos terapêuticos, os participantes cuidam de sua posição profissional comum, em grupos de pares. Cuidar quer dizer aqui situar-se em uma dimensão narcísica e ocupar-se de si, restaurar-se, em um duplo movimento que concerne a si e ao outro. O olhar e a escuta dos pares, convidados à exposição de situações e às elaborações psíquicas, favorecem as simbolizações possíveis nos relatos e nas associações. As temáticas ligadas às dinâmicas persecutórias ou depressivas ligadas às relações com os alunos, a instituição, a culpabilidade, ao medo, tomam outro sentido. Esse efeito de cuidado deve-se aos deslocamentos que se produzem no relato, no mais íntimo e no mais partilhado, por meio das transferências em jogo no grupo. As defesas profissionais abrandam-se e reorganizam-se de outro modo - assim, atenua-se a diferença entre o si aluno e o si docente - sua colocação em ligação sociabiliza um sofrimento ou uma culpabilidade interna, por exemplo, a propósito da agressividade sentida em relação aos alunos e que se torna consciente. 
As ligações psíquicas que se constroem com a fala e o a mágoa dos profissionais levantam certos recalcamentos e favorecem a circulação das identificações. Nessa condição, certas repetições inconscientes - ligadas ao passado do aluno ou à história familiar, ambas ativas no trabalho atual podem ser trabalhadas.

\section{Conclusão}

Os paradoxos instituem a psicanálise. Freud construiu um dispositivo em que o cuidado, o terapêutico, estão fundamentalmente ligados ao desejo de compreender e de conhecer, por exemplo, a gênese dos sintomas. A obra freudiana sempre ligou sua dimensão de pesquisa com os progressos da terapêutica. A idéia da educação terapêutica permite assim novas confrontações entre psicanálise e educação. Os primeiros educadores, como Aichorn, utilizavam a experiência ou o saber psicanalítico como uma ferramenta para melhorar a educação, estabelecer laços com as crianças e os adolescentes incompreensíveis e que caminhavam mal.

O entre-dois do cuidado e da educação e suas diferentes formas é sem dúvida um cadinho em que se processa o debate entre a psicanálise e a educação, presente desde a origem. Ele concerne às crianças, aos adolescentes, mas também aos adultos profissionais que buscam compreender certas moções psíquicas de sua profissão. Quando Herbert Graf, ex “pequeno Hans”, reencontra Freud, ele lhe diz que havia esquecido seu "tratamento" e que não se lembrava de nada do que havia relatado no relato de seu caso. Essa amné- sia, sinal de um recalcamento bem sucedido, é freqüente nas crianças. Com elas, a terapia reencontra a educação, que se constrói com as identificações que ela põe em cena. O efeito terapêutico é acompanhado, talvez, de uma liberação pulsional que se exprime talvez violentamente contra os modelos educativos mal integrados, mesmo que os pais esperassem do tratamento uma criança ideal, pacificada, correspondendo a suas expectativas. Se compararmos os dois domínios estudados, a terapia analítica da criança incide sobre a parte educativa que está a construir-se nele, em ligação com as identificações, em particular, as familiares. Com os profissionais e os docentes, os grupos clínicos reativam o infantil para reconduzir a seu lugar a função docente e sua parte educativa, em que se reúnem os conflitos ligados a um passado profissional ou pessoal, na relação à tarefa presente.

É, com efeito, no terreno das identificações e freqüentemente pelas condutas narcísicas que a terapia analítica e a formação clínica se encontram, que os laços com a criança em tratamento, com os docentes em ligação com os alunos e o saber se reorganizam. De fato, a cada vez, trata-se de fazer funcionar uma dimensão de reconhecimento inconsciente de imagens de si e do outro, carregados de idealização, de decepção - quer elas sejam as do docente e do aluno, quer da criança e dos pais adultos.

O que é a terapêutica? A desaparição do sintoma? Em uma ótica não psicanalítica, tanto no nível terapêutico como no educativo, evocaríamos o recurso às identificações corretivas, as modelizações. E, no entanto, o que 
quer dizer o cuidado na análise: a ordenação do sofrimento e das defesas? O abrandamento das clivagens? A terapêutica retorna aqui ao cuidado, ao care, à preocupação com o outro e não ao restabelecimento da saúde. Uma melhor integração ou subjetivação são os elementos reconhecidos como terapêuticos pelos clínicos.

Enfim, e esta seria uma pista para reflexão futura a ser elaborada, em um plano mais global, pode-se sublinhar que a aceitação do quadro clínico do tratamento, da relação ao desejo do analista, faz com que haja aí formação, isto é, transformação de sujeito. Educa-se ou inicia-se nessa experiência que freqüentemente não deixa senão poucos traços conscientes, a não ser que se mobilize em seguida um desejo de pesquisa ou um uso dessa experiência para orientar-se na direção da prática clínica. Os efeitos terapêuticos, a redução da angústia, esquecer as condições de produção dessa melhora na qual se introjetou uma experiência conduzida em um dispositivo sustentado no tempo. A educação terapêutica não designaria então outra vertente que a de uma "educação ao inconsciente", uma educação aos processos inconscientes experienciados em um quadro, sustentados por hipóteses, por teorias que inscrevem na cultura uma nova concepção da subjetividade e do humano.

\section{Abstract}

THE BONDS BETWEEN CARE AND EDUCATION: CURRENT CLINICAL PRACTICES

This article intends to describe the bonds between care and education, according to a clinical and psychoanalytical approach. Two domains are

studied, that of the psychotherapies of the children and that of the teachers in training, from transferentail dynamics. The clinical animation of teacher's groups shows therapeutic effects on the psychic world of teachers and professional and personal suffering. This double dimension of care and self experience is present since the foundation of the psychoanalysis. INDEX TERMS: transference; psychotherapy of child; teacher clinical training

\section{RESUMEN}

LA POLÉMICA ENTRE EL CUIDADO TERAPÉUTICO Y LA EDUCACIÓN. NUEVAS PERSPECTIVAS

Intentase mostrar a partir de una aproximación clínica y psicoanalitica la relación entre lo terapéutico y lo educativo. Estudiase la dimensión tranferencial inherente a la psicoterapia de niños y a la formación de maestros y educadores. La coordinación clinica de grupos con docentes revela los efectos terapéuticos sobre el mundo psíquico de los adultos que atraviesan un estado de sufrimiento profesional y personal. Esa doble dimensión de cuidado e de experiencia de si está presente en la propia invención del psicoanálisis.

Palabras Claves: transferencia; psicoterapia de niños; formación clínica

\section{REFERÊNCIAS BIBLIOGRÁFICAS}

Blanchard-Laville, C., Chaussecourte, P., Hatchuel, F. \& Pechberty, B. (2005). Recherches cliniques d'orientation psychanalytique dans le champ de l'éducation et de la formation. Note de synthèse. Revue française de pédagogie,(151), 111-162.

Kupfer, M. C. (2001). La scolarisation des enfants psychotiques au Brésil envisagée comme thérapeutique: une pratique clinique au Brésil, document personnel.

Mendel, G. (1993). Les enseignants et le deuil interminable de l'autorité. Cabiers pédagogiques, (379), 16-18.

Pechberty, B. (2000). L'infantile et la clinique de l'enfant. Col. Psychismes. Paris: Dunod.

Tustin, F. (1986). Le trou noir de la psyché. Paris: Seuil.

Winnicott, D. W. (1971). Jeu et réalité. Paris: Gallimard. 